Western University

Scholarship@Western

Human Environments Analysis Lab (HEAL)

$12-2015$

The effect of leisure-time physical activity on obesity, diabetes, high BP and heart disease among Canadians: Evidence from $2000 / 01$ to $2005 / 06$

Sisira Sarma

Rose Anne Devlin

Jason A. Gilliland

m. Karen Campbell

Gregory S. Zaric 


\title{
THE EFFECT OF LEISURE-TIME PHYSICAL ACTIVITY ON OBESITY, DIABETES, HIGH BP AND HEART DISEASE AMONG CANADIANS: EVIDENCE FROM 2000/2001 TO 2005/2006
}

\author{
SISIRA SARMA $^{\mathrm{a}, *}$, ROSE ANNE DEVLIN $^{\mathrm{b}}$, JASON GILLILAND $^{\mathrm{c}}$, M. KAREN CAMPBELL ${ }^{\mathrm{a}}$ \\ and GREGORY S. ZARIC ${ }^{\mathrm{d}}$ \\ ${ }^{a}$ Department of Epidemiology and Biostatistics, University of Western Ontario, London, Canada \\ ${ }^{\mathrm{b}}$ Department of Economics, University of Ottawa, Ottawa, Canada \\ ${ }^{c}$ Department of Geography, University of Western Ontario, London, Canada \\ ${ }^{\mathrm{d}}$ Ivey Business School, University of Western Ontario, London, Canada
}

\begin{abstract}
Although studies have looked at the effect of physical activity on obesity and other health outcomes, the causal nature of this relationship remains unclear. We fill this gap by investigating the impact of leisure-time physical activity (LTPA) and workrelated physical activity (WRPA) on obesity and chronic conditions in Canadians aged 18-75 using instrumental variable and recursive bivariate probit approaches. Average local temperatures surrounding the respondents' interview month are used as a novel instrument to help identify the causal relationship between LTPA and health outcomes. We find that an active level of LTPA (i.e. walking $\geq 1 \mathrm{~h} /$ day) reduces the probability of obesity by five percentage points, which increases to 11 percentage points if also combined with some WRPA. WRPA exhibits a negative effect on the probability of obesity and chronic conditions. Copyright (0) 2014 John Wiley \& Sons, Ltd.
\end{abstract}

Received 11 September 2013; Revised 21 August 2014; Accepted 22 August 2014

JEL Classification: I10; I12; I18; J18; C23

KEY WORDS: obesity; physical activity; chronic disease; probit; instrumental variable; recursive bivariate probit; Canada

\section{INTRODUCTION}

Research shows that leisure-time physical activity (LTPA) is associated with lower risks of obesity, preventable chronic diseases and premature mortality (US Department of Health and Human Services, 1996; Craig et al., 2005; Chen and Mao, 2006; Tjepkema, 2006; Warburton et al., 2006; Brown et al., 2007; Ross et al., 2007; Godley and McLaren, 2010). Although interesting, these associations may not be casual because the decision to participate in LTPA and its duration are correlated with unobservable factors like the enjoyment of physical activity, time preference, opportunity cost of time and risk aversion (Komlos et al., 2004; Smith et al., 2005; Norton and Han, 2008). The decision to participate in LTPA may also be correlated with other behaviours like healthy eating. Consequently, physical activity is potentially an endogenous variable in health-related outcome equations, similar to that found between other lifestyle variables and health (Contoyannis and Jones, 2004; Balia and Jones, 2008; Schneider and Schneider, 2012).

If individuals were randomly assigned into different physical activity levels, the limitation of unobservable confounders being correlated with LTPA and health outcomes could be overcome. Such large-scale experiments are

*Correspondence to: Department of Epidemiology and Biostatistics, Schulich School of Medicine and Dentistry, the University of Western Ontario, London, Ontario, N6A 5C1, Canada. E-mail: ssarma2@uwo.ca 
difficult to conduct. Thus, one has to rely on observational data to estimate the effect of LTPA on obesity and chronic diseases. An instrumental variable (IV) method of estimation can purge endogeneity bias if exogenous instruments are correlated with LTPA but uncorrelated with the error term in the relevant health outcome equations.

To the best of our knowledge, only Humphreys et al. (2014) employed such a methodology in their recursive bivariate probit modelling framework. Using self-reported 'sense of belonging to the local community' as an exclusion restriction, they show that participation in LTPA reduces the probability of diabetes, high blood pressure (BP), heart disease, asthma, arthritis and self-reported poor health. However, studies have shown that the 'sense of belonging to the local community' is associated with better health outcomes in Canada (Ross, 2002; Wister and Wanless, 2007; Shields, 2008; Kitchen et al., 2011; Romans et al., 2011) and higher social capital (Wister and Wanless, 2007; Laporte et al., 2008; Kitchen et al., 2011). Thus, the exogeneity of the sense of belonging variable is called into question as it appears to be correlated with both the LTPA and health outcomes. Our study employs a hitherto unexploited exogenous instrument, the monthly average temperatures in the respondents' local neighbourhood, which is highly correlated with LTPA but uncorrelated with the error term in the outcome equations.

Most studies fail to consider work-related physical activities (WRPAs) when examining the effects of LTPA, and vice versa (Fogelholm and Kukkonen-Harjula, 2000; Wareham et al., 2005; Summerbell et al., 2009). For instance, Humphreys et al. acknowledge the importance of WRPA but ignore it in their analysis, which may cause specification bias. Our paper examines the effects of both LTPA and WRPA on obesity and chronic diseases; additionally, we look at how the effect of LTPA varies across three distinct levels of WRPA: (i) sedentary; (ii) stand/walk; and (iii) lift light or heavy loads.

Finally, our paper contributes to the existing literature by the use of consistent and high-quality information on LTPA over time. A number of studies rely on a global self-reported physical activity measure that may be a good proxy for participation but ignores the intensity, frequency and duration of physical activity (Wareham et al., 2005). Our study captures these three elements.

\section{THEORETICAL MOTIVATION AND EMPIRICAL METHODOLOGY}

The theoretical underpinning of this study is based on Grossman's model where rational individuals make decisions about how to allocate their time to produce health in order to maximize lifetime utility, subject to constraints (Grossman, 2000). Accordingly, healthy behaviours, like regular exercise, are regarded as investments in the production of good health. The stock of health, $H$, is produced by individuals according to the production technology: $H=H(L, E, X, u)$, where $L$ represents lifestyles that include regular exercise and other health-related behaviours, $E$ represents educational status (affecting gross investments in health), $X$ denotes variables influencing either the depreciation rate or the productivity of investments (e.g. age and sex), and $u$ represents individual-specific unobservables affecting the stock of health. In this framework, the opportunity costs of time and preferences will influence decisions regarding exercise, including its intensity and duration (Mullahy and Robert, 2010; Brown and Roberts, 2011; Humphreys and Ruseski, 2011; Maruyama and Yin, 2012). While time spent on physical activity is a source of disutility because of opportunity costs, it may serve to enhance discounted lifetime utility by increasing the availability of healthy days in future periods. Furthermore, the opportunity cost of time will be lower for those who enjoy physical activity (Hatziandreu et al., 1988; Hagberg and Lindholm, 2010). The key point is that unobservable factors will likely affect both physical activity and health outcomes.

Our empirical specification is similar to the reduced-form model of Humphreys et al. (2014). We use three econometric approaches: a univariate probit model, an IV model and a recursive bivariate probit model.

\subsection{Univariate probit model}

We begin with a reduced-form model of obesity (or chronic disease) a la Humphreys et al. (2014), but in which we include WRPA 


$$
H_{i}^{*}=\alpha+\delta_{1}(L T P A)_{i}+\delta_{2}(W R P A)_{i}+\beta^{\prime} X_{i}+\varepsilon_{i} .
$$

For each individual $i, H_{\mathrm{i}}^{*}$ is the latent health stock, $L T P A_{i}$ and $W R P A_{i}$ are as previously defined, $X_{\mathrm{i}}$ is a vector of demographic and socio-economic characteristics and $\varepsilon_{\mathrm{i}}$ is the standard disturbance term. We do not observe $H_{\mathrm{i}}^{*}$; instead, we observe $H_{\mathrm{i}}=1$ if $H_{\mathrm{i}}^{*} \geq 1$ and 0 otherwise. We consider five dichotomous $H_{\mathrm{i}}$ variables: overweight, obesity, diabetes, high BP, and heart disease. Like Humphreys et al., three variables reflect participation and the intensity of LTPA: (i) daily; (ii) moderate; and (iii) active. Our WRPA measure consists of four dummy variables (including the reference case) based on responses to the question 'thinking back over the past 3 months, which of the following best describes your usual daily activities or work habits? : i) usually sit during the day and don't walk around very much (defined as sedentary) ii) stand or walk quite a lot during the day but don't have to carry or lift things very often (defined as stand/walk), iii) usually lift or carry light loads, or have to climb stairs or hills often (defined as light load), and iv) do heavy work or carry very heavy loads (defined as heavy load)'.

A probit regression model of Eqn (1) provides our baseline analysis. The estimated coefficient, $\hat{\delta}_{1}$, measures the impact of LTPA on $H_{i}$. Because LTPA is a dichotomous variable, its average partial effect is the sample average of changes in the predicted probability of being obese or having a chronic condition with discrete changes in LTPA, while evaluating all other variables, $X_{\mathrm{i}}$, at their observed values. It is computed as

$$
\frac{1}{n} \sum_{1}^{n}\left[\Phi\left(\hat{\beta} X_{i}+\hat{\delta}_{2}\left(W R P A_{i}\right)+\hat{\delta}_{1}\left(L T P A_{i}\right) \mid L T P A=1\right)-\Phi\left(\hat{\beta} X_{i}+\hat{\delta}_{2}\left(W R P A_{i}\right)+\hat{\delta}_{1}\left(L T P A_{i}\right) \mid L T P A=0\right)\right],
$$

where $\Phi$ is the standard normal distribution function and $\Phi\left(\hat{\beta} X+\delta_{1} \hat{L T P A}+\delta_{2} \hat{W R P A}\right)$ is the marginal predicted probability of participating in LTPA (or the intensity of LTPA) and is computed for each observation using the estimated coefficients from Eqn (1); $n$ is the sample size. The average partial effects of WRPA are similarly computed.

\subsection{Instrumental variable model}

The main drawback of the univariate probit model is that the decision to participate in LTPA or its intensity is unlikely to be exogenous as unobservable factors like the enjoyment of physical activity, time preference and the opportunity cost of time are likely to be correlated with both LTPA and $H_{i}$. ${ }^{1}$ Allowing LTPA to be endogenous, we respecify Eqn (1) as

$$
H_{i}^{*}=\alpha+\delta_{1}\left(L T P A^{*}\right)_{i}+\delta_{2}(W R P A)_{i}+\beta^{\prime} X_{i}+\varepsilon_{i},
$$

where $L T P A^{*}{ }_{i}$ is the latent variable determining physical activity for individual $i$ (participation or intensity). Thus,

$$
L T P A_{i}^{*}=\eta+\lambda^{\prime} Z_{i}+\gamma^{\prime} X_{i}+u_{i},
$$

where $Z_{i}$ is the vector of characteristics that influence participation in physical activity but are uncorrelated with $\varepsilon_{i}$, $\eta$ is the intercept term, and $u_{i}$ is the error term. We are interested in the consistent estimate of the $\delta$ s. The observed realization of the latent variable $L T P A^{*}{ }_{i}$ takes the following form: $L T P A_{i}=1$ if $L T P A^{*}{ }_{i} \geq 1$ and 0 otherwise.

A common approach to estimating Eqns (3)-(4) is a linear IV procedure if an exogenous instrument can be found that is correlated with LTPA but uncorrelated with $\varepsilon_{i} \mid X$ (Imbens and Angrist, 1994; Angrist et al., 1996). A linear IV generally yields consistent estimates for the local average treatment effect (Imbens and Angrist, 1994; Angrist et al., 1996).

\footnotetext{
${ }^{1}$ WRPA is more likely to be exogenous as it is primarily governed by educational attainment and ability. While it is possible that some people may avoid physically demanding jobs because of particular health conditions, for the most part, one expects education and ability to be the driving forces behind occupational choice.
} 
Researchers typically rely on theoretical justifications and statistical tests for the validity of instruments because the exogeneity assumption is not directly testable. The theoretical basis for our instrument is that an individual's LTPA decisions are governed by unobservable preferences, like the enjoyment of physical activity, which is partly determined by local weather conditions. With large seasonal variations in temperatures across Canada, the average monthly temperature in a respondent's local neighbourhood is likely to be correlated with LTPA and uncorrelated with $\varepsilon_{i} \mid X_{i}$ as levels of LTPA will fluctuate with changes in temperature. Indeed, a systematic review finds that physical activity levels are considerably lower during colder months in countries with extreme weather (Tucker and Gilliland, 2007). Merchant et al. (2007) report that 64\% of Canadians are inactive in the winter compared with $49 \%$ in the summer. Studies also suggest that weather accounts for over $40 \%$ of all measured physical activity (Tucker and Gilliland, 2007). Thus, variations in the local temperature provide a natural setting to study the effects of physical activity on health outcomes. Because our LTPA variable is constructed based on physical activity over a 3-month period, we use corresponding local temperature data by period for each respondent as our instruments. ${ }^{2}$

The Canadian Community Health Survey (CCHS) confidential master files provide access to six-digit residential postal codes and the date of respondent interviews. Monthly weather data for over 1200 weather stations with longitude and latitude coordinates are compiled by Environment Canada and publicly available. ${ }^{3}$ After assigning a local weather station to each respondent, we link local temperatures back 3 months beginning with the interview month. ${ }^{4}$ We restrict our analysis to those observations with a weather station within a 0.5 degree distance (about $55 \mathrm{~km}$ ) from the respondent's home based on the centroid of his/her six-digit postal code. ${ }^{5} \mathrm{Be}$ cause CCHS data were collected over 12 months, large exogenous variations in temperatures around the interview months were found and are used as the source of identification as average temperatures vary considerably in our data from $+25^{\circ} \mathrm{C}$ to $-33^{\circ} \mathrm{C}$ (Appendix Table A1 in Supporting Information).

The IV approach depends on the validity and relevance of the identifying instruments. The validity of the overidentifying restrictions is tested using Hansen's $J$ statistic (Baum et al., 2007). We also test whether the IV estimates suffer from weak or irrelevant instruments (Bound et al., 1995); if the $F$-statistic in the first stage is less than 10 (for a single endogenous variable and one instrument), the instrument is weak (Staiger and Stock, 1997). Stock and Yogo (2005) developed a formal weak-identification $F$-statistic, and a robust counterpart was subsequently developed by Kleibergen and Paap (2006) to examine the bias associated with the IV estimator. These test statistics are compared with the critical values tabulated by Stock and Yogo (2005). Various tests confirm that our instruments satisfy the identification requirements, rejecting the hypothesis that our instruments are weak with a few exceptions.

\subsection{Recursive bivariate probit model}

Although the linear IV method is consistent for estimating the local average treatment effect, it is generally biased and may be inferior to a correctly specified bivariate probit model under certain circumstances. Altonji et al. (2005) found that the linear IV model produced large coefficients and standard errors compared with the bivariate probit model. Some argue that a correctly specified bivariate probit model is superior to the IV procedure, especially if the error term is non-normal (Bhattacharya et al., 2006; Freedman and Sekhon, 2010). Several papers in the health economics literature have utilized recursive bivariate probit models to study the relationship between lifestyle variables and health status (Contoyannis and Jones, 2004; Balia and Jones, 2008; Schneider and Schneider, 2012) and physical activity and health outcomes (Humphreys et al., 2014).

\footnotetext{
${ }^{2}$ Respondents were asked about details of their physical activities in the past 3 months. When the fourth month average temperature was included, it often failed to have explanatory power, suggesting that temperature does indeed affect LTPA.

${ }^{3} \mathrm{http}: / /$ climate.weatheroffice.gc.ca/prods_servs/cdn_climate_summary_e.html

${ }^{4}$ If a respondent was interviewed on January 21, 2001, we link the average temperatures in January 2001, December 2000 and November 2000 from the nearest weather station to this person.

${ }^{5}$ More than $87 \%$ of respondents were assigned to a local weather station with consistent temperature data over a 3-month period. Sensitivity analysis suggested that our results are unaffected within a 0.3 degree (about $33 \mathrm{~km}$ ) to 1 degree (about $111 \mathrm{~km}$ ) range.
} 
Identification in a bivariate probit model rests on exclusion restrictions - that is, excluding at least one variable from the structural equation and including it in the reduced-form equation (Maddala, 1983). Wilde (2000) argues that it is necessary to have at least one varying exogenous regressor in order to avoid identification problems, although exclusion restrictions as such are not required to estimate a bivariate probit model. Conceptually, we think that exclusion restrictions are superior to having an irrelevant exogenous variable or to having identification by functional form. Our instrument constitutes the exclusion restriction. The recursive bivariate probit model is specified as per Eqns (3)-(4) with the additional assumption that $\operatorname{Cov}(\varepsilon, u)=\rho ; \rho$ is interpreted as the conditional tetrachoric correlation between $H$ and LTPA. Average

Table I. Variable definitions

\begin{tabular}{|c|c|}
\hline Variable & Definition \\
\hline Overweight & Bias-corrected BMI $\geq 25 \mathrm{~kg} / \mathrm{m}^{2}=1,0$ if bias-corrected BMI is greater than or equal to $18.5 \mathrm{~kg} / \mathrm{m}^{2}$ and less than $25 \mathrm{~kg} / \mathrm{m}^{2}$ \\
\hline Obese & Bias-corrected $\mathrm{BMI} \geq 30 \mathrm{~kg} / \mathrm{m}^{2}=1,0$ if bias-corrected BMI is greater than or equal to $18.5 \mathrm{~kg} / \mathrm{m}^{2}$ and less than $25 \mathrm{~kg} / \mathrm{m}^{2}$ \\
\hline Diabetes & Reported diagnosis of diabetes $=1$, otherwise $=0$ \\
\hline High BP & Reported diagnosis of high $\mathrm{BP}=1$, otherwise $=0$ \\
\hline Heart disease & Reported diagnosis of heart disease $=1$, otherwise $=0$ \\
\hline Participation & Daily average LTPA lasting more than $15 \min =1$, otherwise $=0$ \\
\hline Moderate & $\begin{array}{l}\text { Average daily energy expenditure on LTPA per kilogram of body weight per day (LTPA_EE) } \geq 1.5 \mathrm{kcal} / \mathrm{kg} / \mathrm{day} \\
\text { (i.e. walk } 30-50 \mathrm{~min})=1 \text {, LTPA_EE }<1.5 \mathrm{kcal} / \mathrm{kg} / \text { day (i.e. walk }<30 \mathrm{~min} \text { ) }=0\end{array}$ \\
\hline Active & LTPA_EE $\geq 3.0 \mathrm{kcal} / \mathrm{kg} /$ day (i.e. walk $\geq 1 \mathrm{~h}$ ) $=1$, LTPA_EE $<1.5 \mathrm{kcal} / \mathrm{kg} / \mathrm{day}$ (i.e. walk $<30 \mathrm{~min}$ ) $=0$ \\
\hline Sedentary & Usually sit during the day and do not walk very much $=1$, otherwise $=0$ \\
\hline Stand/Walk & Usually stand or walk quite a lot during the day but do not have to carry or lift things very often $=1$, otherwise $=0$ \\
\hline Light loads & Usually lift or carry light or heavy loads or have to climb stairs or hills often $=1$, otherwise $=0$ \\
\hline Heavy loads & Usually do heavy work or carry very heavy loads $=1$, otherwise $=0$ \\
\hline Female & Female $=1$, male $=0$ \\
\hline Age & Age in completed years \\
\hline Age squared & Age squared \\
\hline Married & Married or common law relationship $=1$, single $=0$ \\
\hline WSD & Widow, separated or divorced $=1$, single $=0$ \\
\hline Immigrant $\leq 10$ years & Immigrated to Canada less than or equal to 10 years $=1$, Canadian born $=0$ \\
\hline Immigrant $>10$ years & Immigrated to Canada more than 10 years ago $=1$, Canadian born $=0$ \\
\hline$<$ Secondary & Less than secondary school $=1$, otherwise $=0$ \\
\hline Secondary & Secondary school graduation $=1$, otherwise $=0$ \\
\hline$<$ Post-secondary & Some post-secondary education $=1$, otherwise $=0$ \\
\hline Post-secondary & College or university degree $=1$, otherwise $=0$ \\
\hline Children $<6$ years & Children in the household aged less than 6 years $=1$, otherwise $=0$ \\
\hline Children $<12$ years & Children in the household aged 6 years or more but less than 12 years, otherwise $=0$ \\
\hline Employed & Full-time or part-time employed $=1$, otherwise $=0$ \\
\hline Home owner & Household owned a home with or without mortgage $=1$, otherwise $=0$ \\
\hline Income: $<20 \mathrm{k}$ & Household income less than $\$ 20000=1$, otherwise $=0$ \\
\hline Income: $20-50 \mathrm{k}$ & Household income greater than $\$ 20000$ but less than $\$ 50000=1$, otherwise $=0$ \\
\hline Income: $50-80 \mathrm{k}$ & Household income greater than $\$ 50000$ but less than $\$ 80000=1$, otherwise $=0$ \\
\hline Income: $>80 \mathrm{k}$ & Household income greater than $\$ 80000=1$, otherwise $=0$ \\
\hline Income: missing & Household income missing $=1$, otherwise $=0$ \\
\hline Urban & Living in urban area $=1$, rural area $=0$ \\
\hline NFL & Province: Newfoundland $=1$, otherwise $=0$ \\
\hline PEI & Province: Prince Edward Island $=1$, otherwise $=0$ \\
\hline NS & Province: Nova Scotia $=1$, otherwise $=0$ \\
\hline NB & Province: New Brunswick $=1$, otherwise $=0$ \\
\hline QUE & Province: Quebec $=1$, otherwise $=0$ \\
\hline ON & Province: Ontario $=1$, otherwise $=0$ \\
\hline MAN & Province: Manitoba $=1$, otherwise $=0$ \\
\hline SAS & Province: Saskatchewan $=1$, otherwise $=0$ \\
\hline $\mathrm{AL}$ & Province: Alberta $=1$, otherwise $=0$ \\
\hline $\mathrm{BC}$ & Province: British Columbia $=1$, otherwise $=0$ \\
\hline Territories & Province: Yukon, Northwest Territories, or Nunavut $=1$, otherwise $=0$ \\
\hline Cycle 1 & Equal to 1 if surveyed in 2000/2001, 0 otherwise \\
\hline Cycle 2 & Equal to 1 if surveyed in $2003 / 2004,0$ otherwise \\
\hline Cycle 3 & Equal to 1 if surveyed in $2005 / 2006,0$ otherwise \\
\hline
\end{tabular}


Table II. Average partial effects—overweight (full sample)

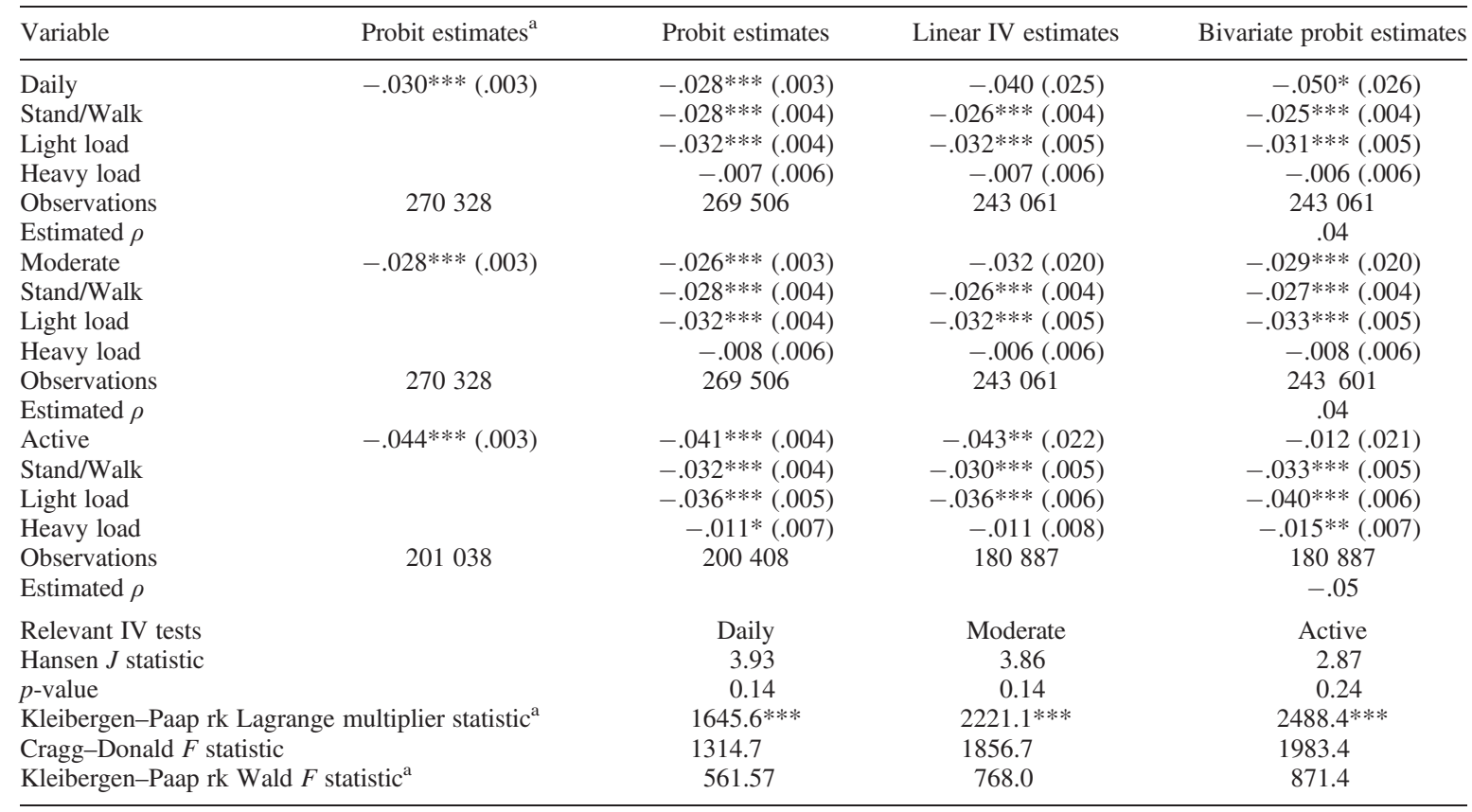

Note: All regressions include the full set of control variables, $X_{\mathrm{i}}$, defined on pages 13-14.

${ }^{a}$ Excludes WRPA.

Robust standard errors in parentheses; $* * * p<0.01 ; * * p<0.05 ; * p<0.1$.

Critical values for Cragg-Donald Wald $F$ statistic: $5 \%$ maximal IV relative bias: $13.91 ; 10 \%$ maximal IV size: 22.30 .

partial effects are obtained similar to that for the probit model using the estimated parameters from the recursive bivariate probit models.

\section{DATA AND VARIABLES}

Data for this study come from three biennial confidential master files of the CCHS, Cycles 1.1 (2000/01), 2.1 (2003/04) and 3.1 (2005/06), conducted by Statistics Canada. Each cycle is a representative survey of more than 130000 individuals aged 12 years or older living in all provinces and territories in Canada, except those living on Crown lands, Indian reserves, Canadian Forces bases, institutions and some remote areas. The surveys were conducted by highly skilled interviewers, with response rates of over $90 \%$. Our sample is restricted to those aged 18 to 75 years. Excluding missing socio-demographic variables other than household income resulted in 315833 valid observations. Sample sizes for the different regression analyses vary by the type of outcome and the chosen sub-sample criteria. All descriptive and regression analyses are weighted using the sampling weights provided by Statistics Canada.

The CCHS contains information on self-reported weight and height for all respondents 18 years and older, excluding pregnant women. However, self-reported height and weight, and hence the body mass index (BMI), ${ }^{6}$ are likely to be biased because individuals generally tend to overreport their height and underreport their weight. Thus, the sex-specific correction factors proposed by Connor et al. (2008) were applied. Overweight has $\mathrm{BMI} \geq 25$, normal has $18.5 \leq \mathrm{BMI}<25$, and obese is $\mathrm{BMI} \geq 30$.

${ }^{6} \mathrm{BMI}$ is weight in kilograms divided by height in metres squared. 
The intensity of LTPA is measured by the average daily energy expended on all leisure activities undertaken over a 3-month period. A list of LTPA options was provided to survey participants to indicate how many times they performed each activity, and average duration, over the past 3 months. Energy expenditure for each respondent is then calculated as LTPA_EE $=\sum_{i}\left(\left(N_{i} * D_{i} * M E T\right) / 365\right)$, where $N_{i}$ is the number of times engaged in activity $i$ during past 12 months, $D_{i}$ is its average duration in hours, and MET is the metabolic energy cost of the activity (a multiple of the resting metabolic rate). The MET values are of three intensity levels: high, medium and low. Because the CCHS did not collect information on the intensity of activities from the respondents, Statistics Canada adopted the low-intensity value for each activity, consistent with the guidelines of the Canadian Fitness and Lifestyle Research Institute: www. cflri.ca. This approach seems reasonable as it is well known that individuals tend to overstate activity intensity when surveyed. $L T P A \_E E$ is expressed as kilocalories expended per kilogram of body weight per day ( $\left.\mathrm{kcal} / \mathrm{kg} / \mathrm{day}\right)$. A person is considered physically inactive if the daily leisure-time energy expenditure is less than $1.5 \mathrm{kcal} / \mathrm{kg} / \mathrm{day}$, moderately active if the energy expenditure is $1.5-2.9 \mathrm{kcal} / \mathrm{kg} / \mathrm{day}$, and active if the energy expenditure is $3.0 \mathrm{kcal} / \mathrm{kg} / \mathrm{day}$ or more. Binary variables capture these levels. Practically speaking, physical inactivity refers to walking less than $30 \mathrm{~min}$ daily; moderate activity is walking 30-59 min daily, while walking $60 \mathrm{~min}$ or more is an 'active' person.

A wide variety of demographic and socio-economic variables are included in all regression models. Table I provides the detailed definitions of all variables used in this paper, and the corresponding descriptive statistics are reported in Appendix B in Supporting Information.

\section{RESULTS}

Because the effects of physical activity on obesity and chronic conditions are our primary focus, we present the results of LTPA and WRPA. Given space constraints, descriptive results and analyses are presented in

Table III. Average partial effects—obese (full sample)

\begin{tabular}{|c|c|c|c|c|}
\hline Variable & Probit estimates $^{\mathrm{a}}$ & Probit estimates & Linear IV estimates & Bivariate probit estimates \\
\hline Daily & \multirow[t]{4}{*}{$-.070 * * *(.004)$} & $-.066^{* * *}(.004)$ & $-.034(.032)$ & $-.057 *(.030)$ \\
\hline Stand/Walk & & $-.051 * * *(.004)$ & $-.053^{* * *}(.005)$ & $-.050 * * *(.005)$ \\
\hline Light load & & $-.058 * * *(.004)$ & $-.065^{* * *}(.006)$ & $-.060 * * *(.006)$ \\
\hline Heavy load & & $-.026^{* * *}(.007)$ & $-.032 * * *(.008)$ & $-.028 * * *(.008)$ \\
\hline Observations & \multirow[t]{2}{*}{166791} & 166284 & 150016 & 150016 \\
\hline Estimated $\rho$ & & & & -.02 \\
\hline Moderate & \multirow[t]{4}{*}{$-.073 * * *(.003)$} & $-.068 * * *(.003)$ & $-.028(.025)$ & $-.025(.025)$ \\
\hline Stand/Walk & & $-.050 * * *(.004)$ & $-.053^{* * *}(.005)$ & $-.052 * * *(.005)$ \\
\hline Light load & & $-.057 * * *(.004)$ & $-.065^{* * *}(.006)$ & $-.064 * * *(.006)$ \\
\hline Heavy load & & $-.026 * * *(.007)$ & $-.033 * * *(.008)$ & $-.031 * * *(.008)$ \\
\hline Observations & \multirow[t]{2}{*}{166791} & 166284 & \multirow[t]{2}{*}{150016} & 150016 \\
\hline Estimated $\rho$ & & & & $-.08 *$ \\
\hline Active & \multirow[t]{4}{*}{$-.108 * * *(.004)$} & $-.101 * * *(.004)$ & $-.065^{* *}(.027)$ & $-.053 * *(.027)$ \\
\hline Stand/Walk & & $-.056 * * *(.005)$ & $-.060 * * *(.006)$ & $-.060 * * *(.006)$ \\
\hline Light load & & $-.062 * * *(.006)$ & $-.070 * * *(.007)$ & $-.069 * * *(.007)$ \\
\hline Heavy load & & $-.034 * * *(.008)$ & $-.045^{* * *}(.009)$ & $-.043 * * *(.009)$ \\
\hline Observations & \multirow[t]{2}{*}{124744} & 124351 & \multirow[t]{2}{*}{112328} & 112328 \\
\hline Estimated $\rho$ & & & & $-.09 *$ \\
\hline \multirow{3}{*}{\multicolumn{2}{|c|}{$\begin{array}{l}\text { Relevant IV tests } \\
\text { Hansen } J \text { statistic } \\
p \text {-value }\end{array}$}} & Daily & Moderate & Active \\
\hline & & 9.42 & 9.3 & 4.83 \\
\hline & & 0.01 & 0.01 & 0.09 \\
\hline \multicolumn{2}{|c|}{ Kleibergen-Paap rk Lagrange multiplier statistic ${ }^{\mathrm{a}}$} & $993.0 * * *$ & $1377.1 * * *$ & $1511.4^{* * *}$ \\
\hline \multicolumn{2}{|c|}{ Cragg-Donald $F$ statistic } & 784.15 & 1144.9 & 1191.9 \\
\hline \multicolumn{2}{|c|}{ Kleibergen-Paap rk Wald $F$ statistic $^{\text {a }}$} & 337.9 & 475.1 & 525.2 \\
\hline
\end{tabular}

Note: all regressions include the full set of control variables, $X_{\mathrm{i}}$, defined on pages $13-14$.

${ }^{a}$ Excludes WRPA.

Robust standard errors in parentheses; $* * * p<0.01 ; * * p<0.05 ; * p<0.1$

Critical values for Cragg-Donald Wald $F$ statistic: 5\% maximal IV relative bias: 13.91; 10\% maximal IV size: 22.30. 
Table IV. Average partial effects—diabetes (full sample)

\begin{tabular}{|c|c|c|c|c|}
\hline Variable & Probit estimates ${ }^{\mathrm{a}}$ & Probit estimates & Linear IV estimates & Bivariate probit estimates \\
\hline Daily & $-.004 * * *(.001)$ & $-.002 *(.001)$ & $.015(.010)$ & $.005(.007)$ \\
\hline Stand/Walk & & $-.012 * * *(.001)$ & $-.017 * * *(.002)$ & $-.013 * * *(.002)$ \\
\hline Light load & & $-.018 * * *(.002)$ & $-.024 * * *(.002)$ & $-.019 * * *(.002)$ \\
\hline Heavy load & & $-.019 * * *(.002)$ & $-.024 * * *(.002)$ & $-.020 * * *(.003)$ \\
\hline Observations & 299159 & 298250 & 268825 & 268825 \\
\hline Estimated $\rho$ & & & & -.06 \\
\hline Moderate & $-.010 * * *(.001)$ & $-.008 * * *(.001)$ & $.012(.008)$ & $.007(.007)$ \\
\hline Stand/Walk & & $-.011 * * *(.001)$ & $-.017 * * *(.002)$ & $-.013 * * *(.002)$ \\
\hline Light load & & $-.017 * * *(.002)$ & $-.024 * * *(.002)$ & $-.019 * * *(.002)$ \\
\hline Heavy load & & $-.018 * * *(.002)$ & $-.023 * * *(.002)$ & $-.020 * * *(.003)$ \\
\hline Observations & 299159 & 298250 & 268825 & 268825 \\
\hline Estimated $\rho$ & & & & $-.12 * * *$ \\
\hline Active & $-.014 * * *(.001)$ & $-.011 * * *(.001)$ & $.016 *(.009)$ & $.008(.007)$ \\
\hline Stand/Walk & & $-.012 * * *(.001)$ & $-.021 * * *(.002)$ & $-.015 * * *(.002)$ \\
\hline Light load & & $-.018 * * *(.002)$ & $-.028 * * *(.002)$ & $-.022 * * *(.002)$ \\
\hline Heavy load & & $-.020 * * *(.003)$ & $-.027 * * *(.002)$ & $-.022 * * *(.003)$ \\
\hline Observations & 223257 & 222557 & 200723 & 200723 \\
\hline Estimated $\rho$ & & & & $-.14 * * *$ \\
\hline \multirow{3}{*}{\multicolumn{2}{|c|}{$\begin{array}{l}\text { Relevant IV tests } \\
\text { Hansen } J \text { statistic } \\
p \text {-value }\end{array}$}} & Daily & Moderate & Active \\
\hline & & 3.67 & 3.7 & 5.2 \\
\hline & & 0.16 & 0.16 & 0.07 \\
\hline \multicolumn{2}{|c|}{ Kleibergen-Paap rk Lagrange multiplier statistic ${ }^{a}$} & $1794.1 * * *$ & $2394.2^{* * *}$ & $2675.6^{* * *}$ \\
\hline \multicolumn{2}{|c|}{ Cragg-Donald $F$ statistic } & 1437.0 & 2004.4 & 2143.9 \\
\hline \multicolumn{2}{|c|}{ Kleibergen-Paap rk Wald $F$ statistic ${ }^{a}$} & 612.7 & 827.7 & 936.4 \\
\hline
\end{tabular}

Note: all regressions include the full set of control variables, $X_{\mathrm{i}}$, defined on pages $13-14$.

${ }^{a}$ Excludes WRPA.

Robust standard errors in parentheses; $* * * p<0.01 ; * * p<0.05 ; * p<0.1$.

Critical values for Cragg-Donald Wald $F$ statistic: $5 \%$ maximal IV relative bias: $13.91 ; 10 \%$ maximal IV size: 22.30 .

Appendix C in Supporting Information. The estimated average partial effects on the probability of being overweight or obese or having diabetes, high BP or heart disease are presented in Tables II-VI respectively. ${ }^{7}$ Each table presents the results of four regression models: Column 2 presents the probit estimates omitting WRPA, column 3 presents the probit estimates including WRPA, column 4 presents the linear IV estimates, and finally, column 5 reports the results from the recursive bivariate probit model. The linear IV and recursive bivariate probit without WRPA estimates are presented in Appendix D in Supporting Information. Note that the probability of overweight refers to overweight or obesity, and the probability of obesity refers only to obesity in our analysis, where the comparison group is normal weight in both cases.

\subsection{Univariate probit results}

From column 2 of Tables II-VI, the estimated average partial effects of daily, moderate and active levels without controlling for WRPA are slightly higher than otherwise, suggesting that failing to control for WRPA may bias upwards the associations between LTPA and health outcomes. Previous literature that has ignored the influence of WRPA on obesity or chronic conditions may overstate the impact of LTPAs on weight and other chronic conditions.

After controlling for WRPA (column 3 of Tables II-VI), we see that both LTPA and WRPA exert a negative influence on the probability of being overweight and obese and having chronic conditions. Each of daily, moderate and active levels of LTPA participation is associated with a 2.8, 2.6 and $4.1 \%$ decrease in the probability of being overweight and 6.6, 6.8 and $10.1 \%$ decrease in the probability of obesity respectively. Compared with sedentary WRPA, being able to stand or walk as well as lift light loads is associated

${ }^{7}$ Detailed regression results are available from the corresponding author upon request. 
Table V. Average partial effects—high BP (full sample)

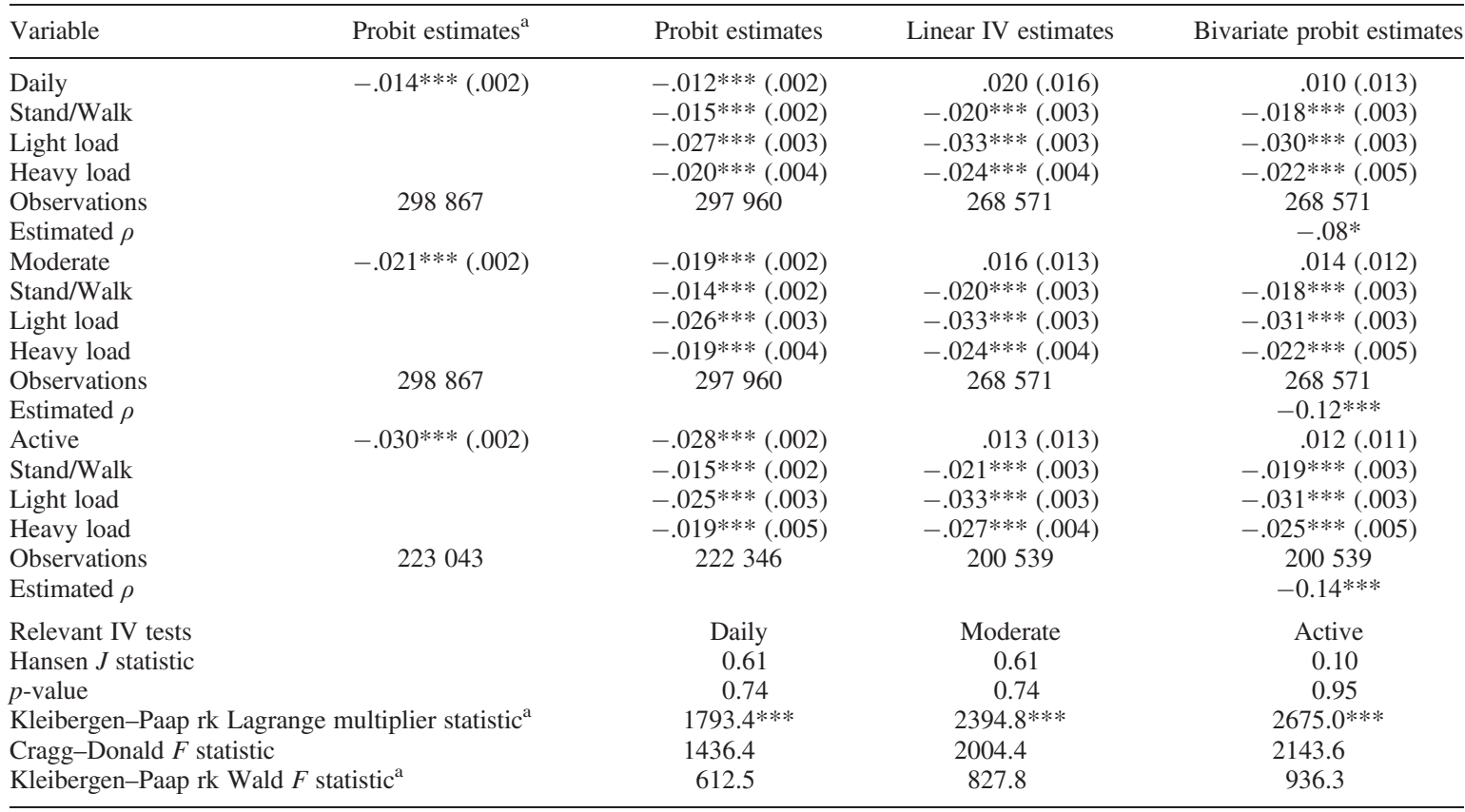

Note: all regressions include the full set of control variables, $X_{\mathrm{i}}$, defined on pages $13-14$.

${ }^{a}$ Excludes WRPA.

Robust standard errors in parentheses; $* * * p<0.01 ; * * p<0.05 ; * p<0.1$

Critical values for Cragg-Donald Wald F statistic: $5 \%$ maximal IV relative bias: $13.91 ; 10 \%$ maximal IV size: 22.30.

with a decrease in the probability of being overweight of three percentage points and a reduction in the probability of obesity by five to six percentage points. However, lifting heavy loads is associated with about a three percentage point decrease in the probability of obesity, but it is not statistically significant for individuals who are overweight.

Participation in LTPA is also negatively associated with the probability of chronic conditions, with daily participation associated with a decrease in the probability of diabetes, high BP and heart disease by $0.2,1.2$ and $0.4 \%$ respectively; a moderate level of LTPA is associated with a decrease of $0.8,1.9$ and $0.6 \%$ respectively, and an active level of LTPA is associated with decreases of 1.1, 2.8 and $0.8 \%$ respectively. Being able to stand or walk and being able to lift light loads and heavy loads are associated with a decrease in the probability of diabetes, high BP and heart disease in the range of 1-2\% when compared with sedentary WRPA.

The results of the probit models suggest that both LTPA and WRPA tend to reduce the probability of being overweight or obese or having diabetes, high BP and heart disease. However, the key question is as follows: Can these results be interpreted as causal effects? We now turn to the linear IV and recursive bivariate probit results that account for endogeneity bias and hence allow us to ascertain causal effects. We find that taking into consideration the unobservable factors affecting an individual's participation in or intensity of physical activity has a large impact on the resulting estimates.

\subsection{Linear IV and recursive bivariate probit results}

A discussion of the identification tests for our instruments is presented in Appendix E in Supporting Information. Contrary to the probit results, the linear IV results show that daily and moderate LTPA does not reduce the probability of being overweight and of obesity. These results are largely confirmed by the recursive bivariate probit models except that a moderate level reduces the probability of being overweight by $2.9 \%$, and the effect 
Table VI. Average partial effects-heart disease (full sample)

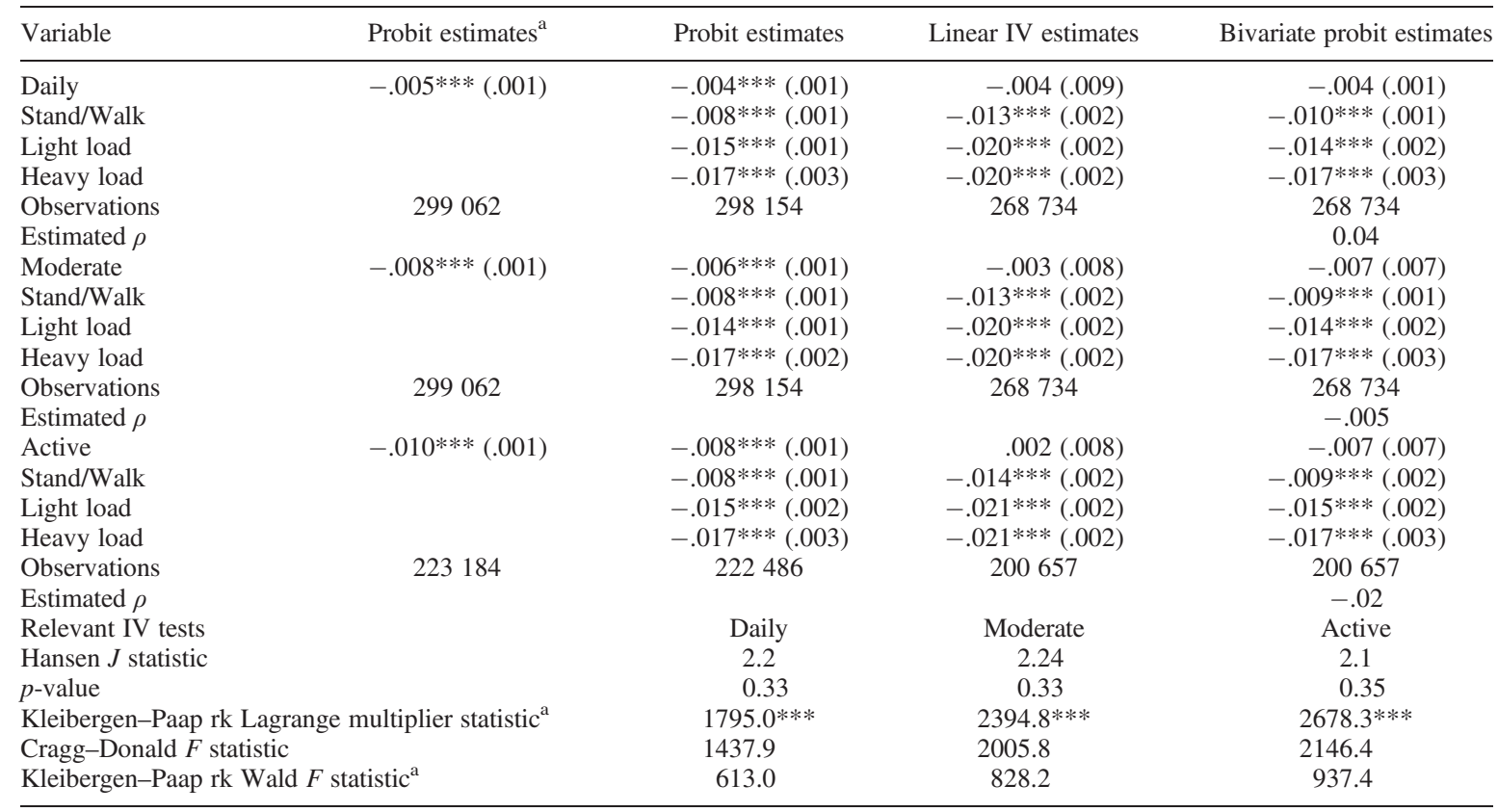

Note: all regressions include the full set of control variables, $X_{\mathrm{i}}$, defined on pages 13-14.

${ }^{a}$ Excludes WRPA

Robust standard errors in parentheses; *** $p<0.01 ; * * p<0.05 ; * p<0.1$.

Critical values for Cragg-Donald Wald $F$ statistic: 5\% maximal IV relative bias: 13.91; 10\% maximal IV size: 22.30.

Table VIIa. Average partial effects—-probit estimates (by WRPA status)

\begin{tabular}{|c|c|c|c|c|c|}
\hline WRPA/LTPA & Overweight & Obese & Diabetes & High BP & Heart disease \\
\hline \multicolumn{6}{|c|}{ WRPA: sedentary } \\
\hline Daily & $-.033^{* * *}(.006)$ & $-.080 * * *(.008)$ & $-.002(.003)$ & $-.015^{* * *}(.004)$ & $-.008 * * *(.003)$ \\
\hline Observations & 61201 & 38953 & 68390 & 68315 & 68370 \\
\hline Moderate & $-.037 * * *(.006)$ & $-.091 * * *(.007)$ & $-.013 * * *(.003)$ & $-.023 * * *(.004)$ & $-.009 * * *(.002)$ \\
\hline Observations & 61201 & 38953 & 68390 & 68315 & 68370 \\
\hline Active & $-.047 * * *(.008)$ & $-.123 * * *(.010)$ & $-.019 * * *(.004)$ & $-.037 * * *(.006)$ & $-.016^{* * *}(.004)$ \\
\hline Observations & 46690 & 29984 & 52710 & 52652 & 52689 \\
\hline \multicolumn{6}{|c|}{ WRPA: stand/walk } \\
\hline Daily & $-.033 * * *(.004)$ & $-.065^{* * *}(.005)$ & $-.001(.002)$ & $-.011 * * *(.003)$ & $-.002(.002)$ \\
\hline Observations & 116350 & 71834 & 130444 & 130348 & 130390 \\
\hline Moderate & $-.028 * * *(.004)$ & $-.064 * * *(.005)$ & $-.008 * * *(.002)$ & $-.020 * * *(.003)$ & $-.006^{* * *}(.002)$ \\
\hline Observations & 116350 & 71834 & 130444 & 130348 & 130390 \\
\hline Active & $-.046^{* * *}(.005)$ & $-.101 * * *(.007)$ & $-.011 * * *(.002)$ & $-.028 * * *(.003)$ & $-.006 * * *(.002)$ \\
\hline Observations & 85208 & 52886 & 95695 & 95618 & 95659 \\
\hline \multicolumn{6}{|c|}{ WRPA: lift light/ heavy load } \\
\hline Daily & $-.017 * * *(.005)$ & $-.053^{* * *}(.006)$ & $-.002(.002)$ & $-.009 * * *(0.003)$ & $-.0006(.001)$ \\
\hline Observations & 91955 & 55497 & 99416 & 99297 & 99394 \\
\hline Moderate & $-.013^{* * *}(.005)$ & $-.050^{* * *}(.006)$ & $-.002(.002)$ & $-.013 * * *(.003)$ & $-.002(.001)$ \\
\hline Observations & 91955 & 55497 & 99416 & 99297 & 99394 \\
\hline Active & $-.028 * * *(.006)$ & $-.082^{* * *}(.007)$ & $-.004 * *(.002)$ & $-.019 * * *(.003)$ & $-.002(.002)$ \\
\hline Observations & 68510 & 41481 & 74152 & 74076 & 74138 \\
\hline
\end{tabular}

Note: all regressions include the full set of control variables, $X_{\mathrm{i}}$, defined on pages 13-14.

Robust standard errors in parentheses; $* * * p<0.01$; ** $p<0.05 ; * p<0.1$. 
Table VIIb. Estimated coefficients—-linear IV estimates (by WRPA status)

\begin{tabular}{|c|c|c|c|c|c|}
\hline WRPA/LTPA & Overweight & Obese & Diabetes & High BP & Heart Disease \\
\hline \multicolumn{6}{|l|}{ WRPA: sedentary } \\
\hline Daily & $.044(.060)$ & $.089(.079)$ & $.032(.026)$ & $.046(.038)$ & $.037(.025)$ \\
\hline Observations & 55044 & 35043 & 61489 & 61428 & 61470 \\
\hline Hansen $J$ statistic & $3.09[0.21]$ & $6.83[0.03]$ & $3.1[0.21]$ & $1.4[0.50]$ & $1.9[0.38]$ \\
\hline $\begin{array}{l}\text { K-P rk Lagrange multiplier } \\
\text { (LM) statistic }\end{array}$ & $316.4 * * *$ & $180.9^{* * *}$ & $331.5 * * *$ & $331.6 * * *$ & $331.1 * * *$ \\
\hline Cragg-Donald $F$ statistic & 254.0 & 143.9 & 267.7 & 267.8 & 267.4 \\
\hline K-P rk Wald $F$ statistic & 108.1 & 61.54 & 113.0 & 113.0 & 112.8 \\
\hline Moderate & $.037(.050)$ & $.072(.063)$ & $.025(.021)$ & $.037(.032)$ & $.031(.020)$ \\
\hline Observations & 55044 & 35043 & 61489 & 61428 & 61470 \\
\hline Hansen $J$ statistic & $3.1[0.21]$ & $6.8[0.03]$ & $3.2[0.20]$ & $1.5[0.48]$ & $1.8[0.41]$ \\
\hline K-P rk LM statistic & $389.0 * * *$ & $232.0 * * *$ & $404.8 * * *$ & $404.5^{* * *}$ & $404.5 * * *$ \\
\hline Cragg-Donald $F$ statistic & 324.8 & 193.2 & 337.0 & 336.5 & 336.7 \\
\hline K-P rk Wald $F$ statistic & 133.6 & 80.1 & 138.8 & 138.6 & 138.6 \\
\hline Active & $.031(.055)$ & $.054(.071)$ & $.050 *(.026)$ & $.039(.036)$ & $.036(.024)$ \\
\hline Observations & 42145 & 27091 & 47543 & 47498 & 47522 \\
\hline Hansen $J$ statistic & $7.3[0.03]$ & $8.9[0.01]$ & $3.0[0.22]$ & $1.9[0.38]$ & $1.1[0.58]$ \\
\hline K-P rk LM statistic & $416.2 * * *$ & $252.3 * * *$ & $429.2 * * *$ & $429.3^{* * *}$ & $428.8 * * *$ \\
\hline Cragg-Donald $F$ statistic & 349.5 & 206.7 & 364.1 & 364.5 & 364.0 \\
\hline K-P rk Wald $F$ statistic & 145.1 & 87.9 & 148.9 & 149.0 & 148.7 \\
\hline \multicolumn{6}{|l|}{ WRPA: stand/walk } \\
\hline Daily & $-.064 *(.038)$ & $-.068(.048)$ & $.008(.015)$ & $.004(.025)$ & $-.020(.015)$ \\
\hline Observations & 104875 & 64722 & 117515 & 117431 & 117464 \\
\hline Hansen $J$ statistic & $0.7[0.69]$ & $3.4[0.18]$ & $1.8[0.42]$ & $0.8[0.67]$ & $0.9[0.65]$ \\
\hline K-P rk LM statistic & $686.0 * * *$ & $394.4 * * *$ & $753.3^{* * *}$ & $753.4 * * *$ & $753.7 * * *$ \\
\hline Cragg-Donald $F$ statistic & 559.1 & 319.0 & 616.0 & 616.2 & 616.5 \\
\hline K-P rk Wald $F$ statistic & 233.8 & 134.4 & 257.2 & 257.2 & 257.3 \\
\hline Moderate & $-.054 *(.031)$ & $-.056(.040)$ & $.006(.013)$ & $.004(.020)$ & $-.016(.012)$ \\
\hline Observations & 104875 & 64722 & 117515 & 117431 & 117464 \\
\hline Hansen $J$ statistic & $0.6[0.74]$ & $3.3[0.19]$ & $1.8[0.40]$ & $0.8[0.68]$ & $0.9[0.65]$ \\
\hline K-P rk LM statistic & $943.1 * * *$ & $562.6 * * *$ & $1020.1 * * *$ & $1021.4 * * *$ & $1020.3 * * *$ \\
\hline Cragg-Donald $F$ statistic & 793.4 & 472.8 & 864.7 & 865.8 & 865.0 \\
\hline K-P rk Wald $F$ statistic & 326.5 & 194.2 & 353.1 & 353.5 & 353.1 \\
\hline Active & $-.072 * *(.032)$ & $-.112 * * *(.040)$ & $-.008(.013)$ & $-.002(.021)$ & $-.004(.013)$ \\
\hline Observations & 76793 & 47672 & 86173 & 86105 & 86140 \\
\hline Hansen $J$ statistic & $0.6[0.75]$ & $0.5[0.76]$ & $1.9[0.38]$ & $1.7[0.43]$ & $0.5[0.79]$ \\
\hline K-P rk LM statistic & $1097.1 * * *$ & $631.3 * * *$ & $1181.4 * * *$ & $1181.5^{* * *}$ & $1181.4^{* * *}$ \\
\hline Cragg-Donald $F$ statistic & 873.7 & 496.8 & 947.1 & 947.4 & 947.4 \\
\hline K-P rk Wald $F$ statistic+ & 386.3 & 219.4 & 415.5 & 415.6 & 415.6 \\
\hline \multicolumn{6}{|l|}{ WRPA: lift light/ heavy load } \\
\hline Daily & $-.062(.040)$ & $-.058(.048)$ & $.022 *(.012)$ & $.031(.022)$ & $-.001(.012)$ \\
\hline Observations & 83142 & 50251 & 89821 & 89712 & 89800 \\
\hline Hansen $J$ statistic & $1.5[0.48]$ & $1.3[0.53]$ & $2.0[0.36]$ & $9.0[0.01]$ & $3.4[0.19]$ \\
\hline K-P rk LM statistic & $659.0 * * *$ & $433.8 * * *$ & $736.9 * * *$ & $735.5^{* * * *}$ & $737.8 * * *$ \\
\hline Cragg-Donald $F$ statistic & 503.6 & 324.8 & 563.3 & 561.9 & 564.0 \\
\hline K-P rk Wald $F$ statistic & 225.2 & 147.5 & 252.6 & 252.1 & 252.9 \\
\hline Moderate & $-.050(.032)$ & $-.046(.038)$ & $.018^{*}(.010)$ & $.023(.018)$ & $-.002(.010)$ \\
\hline Observations & 83142 & 50251 & 89821 & 89712 & 89800 \\
\hline Hansen $J$ statistic & $1.5[0.46]$ & $1.3[0.52]$ & $1.9[0.39]$ & $9.2[0.01]$ & $3.3[0.19]$ \\
\hline K-P rk LM statistic & $920.6 * * *$ & $615.1 * * *$ & $1017.9^{* * *}$ & $1016.9^{* * *}$ & $1019.7 * * *$ \\
\hline Cragg-Donald $F$ statistic & 752.2 & 494.8 & 831.2 & 830.1 & 832.6 \\
\hline K-P rk Wald $F$ statistic & 319.9 & 211.9 & 354.7 & 354.3 & 355.3 \\
\hline
\end{tabular}

(Continues) 
Table VIIb. (Continued)

\begin{tabular}{|c|c|c|c|c|c|}
\hline WRPA/LTPA & Overweight & Obese & Diabetes & High BP & Heart Disease \\
\hline Active & $-.049(.033)$ & $-.072 *(.040)$ & $.015(.010)$ & $.024(.018)$ & $-.003(.010)$ \\
\hline Observations & 61949 & 37565 & 67007 & 66936 & 66995 \\
\hline Hansen $J$ statistic & $0.5[0.78]$ & $0.5[0.78]$ & $2.3[0.31]$ & $7.1[0.03]$ & $3.5[0.17]$ \\
\hline K-P rk LM statistic & $1005.6^{* * *}$ & $653.1 * * *$ & $1108.6^{* * *}$ & $1107.3^{* * *}$ & $1111.8 * * *$ \\
\hline Cragg-Donald $F$ statistic & 769.2 & 500.2 & 851.2 & 849.9 & 853.4 \\
\hline $\mathrm{K}-\mathrm{P}$ rk Wald F statistic & 351.1 & 226.8 & 388.7 & 388.2 & 389.9 \\
\hline
\end{tabular}

Note: all regressions include the full set of control variables, $X_{\mathrm{i}}$, defined on pages 13-14. Figures in square brackets are $p$-values.

K-P, Kleibergen-Paap.

Robust standard errors in parentheses; ***p $<0.01 ; * * p<0.05 ; * p<0.1$

Critical values for Cragg-Donald Wald $F$ statistic

$5 \%$ maximal IV relative bias $\quad 13.91$

$10 \%$ maximal IV relative bias $\quad 9.08$

$20 \%$ maximal IV relative bias $\quad 6.46$

$30 \%$ maximal IV relative bias $\quad 5.31$

$\begin{array}{lr}10 \% \text { maximal IV size } & 22.30 \\ 15 \% \text { maximal IV size } & 12.83 \\ 20 \% \text { maximal IV size } & 9.54 \\ 25 \% \text { maximal IV size } & 7.80\end{array}$

of a daily level is significant at the $10 \%$ level. An active level of LTPA reduces the probability of being overweight and of obesity by 4.3 and $6.5 \%$ respectively based on the linear IV model; however, the bivariate probit results only support the causal link between LTPA and obesity, with the probability of being obese falling by $5.3 \%$ for physically active individuals, but does not support the causal link between LTPA and being overweight. Both linear IV and recursive bivariate probit results show that daily, moderate and active LTPA does not reduce the probability of diabetes, high BP and heart disease. ${ }^{8}$

Similar to the probit results, the WRPA variables are statistically significant predictors of obesity and chronic conditions in both the IV and recursive bivariate probit models. The estimated coefficients on three WRPA variables from the IV models are qualitatively similar to the probit models.

Our results show that WRPAs play an important role in reducing both obesity and chronic diseases. Because these activities are primarily governed by occupation and not easily adjusted by policy levers, programmes aimed at the promotion of workplace wellness, especially in sedentary occupations, may reduce the adverse health effects attributed to leisure-time physical inactivity. Contrary to the probit results, we find that LTPA does not reduce the probability of having chronic conditions. Our results suggest that only an active level of LTPA has the potential to reduce the probability of obesity in the range of five to six percentage points. Although the IV results show that a moderate level of LTPA reduces the probability of being overweight by four percentage points, this finding cannot be confirmed with the bivariate probit model.

\subsection{Interaction of LTPA and WRPA}

Given the limited impact of LTPA on overweight and obesity and its lack of impact on chronic conditions, it is interesting to examine if there is any role to be played by LTPA in combination with WRPA: We wonder if LTPA and WRPA are substitutes or complements. To explore this question, we estimated the effect of LTPA on obesity and chronic conditions across three WRPA sub-groups: sedentary, stand/walk and lift light or heavy load. The estimated results from the probit, linear IV and recursive bivariate probit models are presented in Tables VIIa-VIIc. The econometric test results presented in Table VIIb are consistent with the full sample, suggesting that our instruments are relevant in the sub-group analyses.

The probit results show that each of the daily, moderate and active LTPA is associated with a decrease in the probability of being overweight and obese in all sub-groups. The overall results for sedentary and stand/walk sub-groups are similar to the full-sample results, but the magnitudes of the associations are a bit smaller in the lift

\footnotetext{
${ }^{8}$ The reduced sample sizes in the linear IV and recursive bivariate probit models are because of missing temperature data for one or more periods. To ensure that the simple probit regression results are not an artefact of the larger sample size, we ran the analysis based on our IV samples and did not find appreciable differences in partial effects in the probit models.
} 
Table VIIc. Average partial effects-recursive bivariate probit estimates (by WRPA status)

\begin{tabular}{|c|c|c|c|c|c|}
\hline WRPA/LTPA & Overweight & Obese & Diabetes & High BP & Heart Disease \\
\hline \multicolumn{6}{|c|}{ WRPA: Sedentary } \\
\hline Daily & $.057(.057)$ & $.065(.078)$ & $.013(.021)$ & $.030(.038)$ & $.018(.027)$ \\
\hline Observations & 55044 & 35043 & 61489 & 61428 & 61470 \\
\hline Estimated $\rho$ & -0.16 & $-0.25 *$ & -0.10 & -0.15 & -0.19 \\
\hline Moderate & $.050(.050)$ & $.091(.070)$ & $.004(.017)$ & $.025(.033)$ & $.008(.020)$ \\
\hline Observations & 55044 & 35043 & 61489 & 61428 & 61470 \\
\hline Estimated $\rho$ & $-0.16^{*}$ & $-0.34 * * *$ & -0.13 & -0.16 & -0.13 \\
\hline Active & $.114 * *(.050)$ & $.103(.069)$ & $.010(.019)$ & $.052(.036)$ & $-.014(.022)$ \\
\hline Observations & 42145 & 27091 & 47543 & 47498 & 47522 \\
\hline Estimated $\rho$ & $-0.28^{* * *}$ & $-0.39 * * *$ & $-0.17 *$ & $-0.27 * * *$ & -0.03 \\
\hline \multicolumn{6}{|c|}{ WRPA: stand/walk } \\
\hline Daily & $-.087 * *(.040)$ & $-.108 * *(.048)$ & $.003(.013)$ & $-.006(.022)$ & $-.023(.022)$ \\
\hline Observations & 104875 & 64722 & 117515 & 117431 & 117464 \\
\hline Estimated $\rho$ & 0.09 & 0.07 & -0.04 & -0.02 & 0.16 \\
\hline Moderate & $-.056^{*}(.031)$ & $-.055(.038)$ & $.002(.010)$ & $.001(.020)$ & $-.018(.010)$ \\
\hline Observations & 104875 & 64722 & 117515 & 117431 & 117464 \\
\hline Estimated $\rho$ & 0.05 & -0.02 & -0.08 & -0.07 & 0.08 \\
\hline Active & $-.052 *(.010)$ & $-.121 * * *(.044)$ & $-.0005(.011)$ & $-.004(.011)$ & $-.012(.011)$ \\
\hline Observations & 76793 & 47672 & 86173 & 86105 & 86140 \\
\hline Estimated $\rho$ & 0.01 & 0.03 & -0.08 & -0.09 & 0.03 \\
\hline \multicolumn{6}{|c|}{ WRPA: lift light/ heavy load } \\
\hline Daily & $-.082 * *(.041)$ & $-.079 *(.043)$ & $.010(.009)$ & $.021(.019)$ & $-.002(.010)$ \\
\hline Observations & 83142 & 50251 & 89821 & 89712 & 89800 \\
\hline Estimated $\rho$ & $0.11 *$ & 0.05 & -0.10 & $-0.13^{*}$ & 0.01 \\
\hline Moderate & $-.030(.032)$ & $-.032(.035)$ & $.013 *(.007)$ & $.022(.016)$ & $-.004(.009)$ \\
\hline Observations & 83142 & 50251 & 89821 & 89712 & 89800 \\
\hline Estimated $\rho$ & 0.03 & -0.04 & $-0.15^{* *}$ & $-0.15^{* *}$ & 0.01 \\
\hline Active & $-.049(.034)$ & $-.076 * *(.034)$ & $.006(.007)$ & $.013(.016)$ & $-.007(.009)$ \\
\hline Observations & 61949 & 37565 & 67007 & 66936 & 66995 \\
\hline Estimated $\rho$ & 0.04 & -0.01 & -0.10 & $-0.14 * *$ & 0.04 \\
\hline
\end{tabular}

Note: all regressions include the full set of control variables, $X_{i}$, defined on pages 13-14.

Robust standard errors in parentheses; *** $p<0.01 ; * * p<0.05 ; * p<0.1$.

light or heavy load sub-group. Similar results are also found for diabetes, high BP and heart disease except for the lack of statistical significance for diabetes and heart disease in some instances, particularly in the lift light or heavy load sub-group.

For the linear IV and bivariate probit estimates, except for being overweight and obese in certain subgroups, the statistical significance of LTPA in all other models disappeared. Clearly, LTPA does not cause a reduction in the probability of diabetes, high BP and heart disease regardless of the level of WRPA. From Tables VIIb-VIIc, LTPA has no effect on overweight and obesity among those reported having sedentary WRPA; even an active level of LTPA does not reduce the probability of being overweight and obese, meaning that LTPA and WRPA are not substitutes in this sub-group.

We find that the intensity of LTPA has the greatest effect on obesity among those who also undertake some WRPA like standing or walking. An active level of LTPA reduces the probability of being overweight by about five to seven percentage points, while it reduces the probability of obesity by 11 to 12 percentage points. We also find that daily and moderate levels tend to reduce the probability of being overweight and obese in this sub-group. An active level of LTPA also reduces the probability of being obese by about seven percentage points among those who report lifting light or heavy loads at their work. These results suggest that LTPA and WRPA seem to be complementary in nature as far as the overweight or obesity risk is concerned: Those who report some WRPA and undertake an active level of LTPA reduce the probability of being overweight and obese. 


\section{DISCUSSION AND CONCLUSIONS}

Advances in technological innovations often lead to reductions in the energy expended in the workplace and home environments, but a lack of physical activity is regarded as an important risk factor for obesity and chronic diseases (Weinsier et al., 1998; Fogelholm and Kukkonen-Harjula, 2000; Waxman and Assembly, 2004; Wareham et al., 2005; Summerbell et al., 2009; PHAC, 2011). While a negative association between measures of LTPA and obesity has been found in previous Canadian studies (Craig et al., 2005; Chen and Mao, 2006; Tjepkema, 2006; Ross et al., 2007; Godley and McLaren, 2010), the extent to which these estimates capture a causal relationship is questionable given the endogenous nature of LTPA. To address this problem, we use an IV method of estimation, and we include the potentially confounding role of WRPA using population-based, large health surveys from Canada.

Our paper makes two novel contributions. First, it includes workplace physical activity as well as LTPA in the analysis of physical activity and several health outcomes. Second, it employs a robust estimation strategy to control for the endogeneity of LTPA using respondents' neighbourhood temperatures as a novel identifying instrument. We find that controlling for WRPA results in marginally smaller average partial effects attributable to LTPA on health outcomes. However, once account is taken of the endogeneity of LTPA, we find that it has a large influence on the estimated average partial effects and statistical significance.

WRPA exerts a negative effect on being overweight or obese and having chronic diseases among Canadians aged 18 to 75 years. Consistent with the previous literature, we uncover negative associations between LTPA participation and its intensity and obesity and chronic conditions, but once the endogeneity of LTPA is taken into account, these links become more nuanced. For instance, LTPA does 'not' reduce the probability of overweight and obesity if the WRPA is sedentary. However, an active level of LTPA can cause a reduction in the probability of being overweight and of obesity by five to six percentage points and a reduction in obesity of 11 to 12 percentage points if some WRPA like standing or walking is also in the mix. We also find that intensive WRPA seems to reduce some of the effects of LTPA on obesity, suggesting a reduced marginal effect of LTPA for those engaged in occupations that involve physical strenuousness.

We find that neither LTPA participation nor intensity causes a reduction in the probability of diabetes, high BP and heart disease. By contrast, Humphreys et al. (2014) conclude that participation in LTPA reduces the probability of having diabetes, high BP and heart disease. Specifically, they find that daily, moderate and active LTPA lead to a reduction in the probability of having diabetes by 2.4, 8.5 and 3.4 percentage points respectively and reduction in the probability of having high BP by 3.8, 14.3 and 5.17 percentage points respectively. They also find that moderate LTPA reduces the probability of having heart disease by about 10 percentage points. Although several differences exist between Humphreys et al. (2014) and our study, we think that the use of different instruments is explaining differences in the results. If we exclude WRPA from the model, our results are not at all comparable with Humphreys et al., reinforcing our conclusion that when appropriate instruments are employed, the causal effect of LTPA on diabetes, high BP and heart disease disappears.

Our study does not suggest that intensive physical activity has no role to play in reducing the incidence of chronic conditions. In fact, our results show that moderate WRPAs, like standing or climbing stairs, reduce the probability of having these chronic conditions. However, even an active level of LTPA cannot compensate for sedentary work patterns, underscoring the importance of regular physical activity. The integration of physical activity into daily lives is a crucial factor in reducing the incidence of preventable diseases, like obesity, diabetes, high BP and heart disease.

Although this study has several strengths, there are some limitations. The first concerns the biases introduced by self-reported data. We try to minimize this problem by employing a corrected height and weight measure for the calculation of BMI, although measurement bias will undoubtedly still exist. Self-reported chronic conditions may also be subject to bias, but it is unlikely that this bias will be large. Second, the intensity of physical activities at the individual level was not collected in the CCHS. Although Statistics Canada adopted the low-intensity measure for each activity, having information on the actual intensity at the individual level in future studies would be desirable. A third weakness is that, unlike LTPA, our WRPA variable was based 
on the responses to a single-item question. Detailed data on energy expenditure associated with work-related activities could improve the study and provide a better basis for specific policy recommendations. A fourth weakness is that our exogenous instrument captures primarily the outdoor component of LTPA rather than the entire range of physical activities undertaken by the respondents. Previous literature suggests that over $40 \%$ of measured physical activity can be explained by weather, and hence, variations in temperature are the source of our identification strategy. Our results can be interpreted as the local average treatment effect, which is typical with most IV estimates found in the literature. However, separating the indoor and outdoor components of LTPA in future surveys would provide greater insights. A fifth potential weakness is that the negative relationship between WRPA and obesity and chronic conditions found in this paper could also be attributed to overall lifestyle choices insofar as those who are physically active may also be more inclined to make other healthy choices. Furthermore, the endogeneity of WRPA cannot be ruled out for some segments of the population: Plausible exogenous variation in WRPA levels may provide an avenue for future research in this area. Finally, our analysis is based on three cross-sectional surveys, thereby limiting our ability to account for timeinvariant unobserved heterogeneity. Future studies using longitudinal data can overcome this limitation.

Despite these limitations, our overall results clearly suggest that policies designed to encourage active LTPAs combined with the promotion of physical activity in the workplace will reduce the risk of being overweight or obese. Moreover, the integration of physical activity into daily work lives, especially for those in sedentary occupations, can have a considerable impact on reducing the burden of preventable chronic diseases, thus improving the health of the population. Several policy avenues are possible. Fitness programmes could be facilitated and/or encouraged in the workplace by, for instance, access to free or subsidized gym memberships or by designating spaces for physical activities. Change rooms and/or shower facilities could be provided for employees who exercise during breaks or take physically active travel modes (e.g. bicycling or walking) to work. Programmes like a 'take-the-stairs' type campaign could be launched with various incentives for winning teams, and flexible hours that facilitate early morning or lunchtime activities, can all work towards informing and encouraging a more active workplace environment. The results of our paper suggest that a little effort in this regard has the potential to make a big difference to the health of individuals.

\section{ACKNOWLEDGEMENTS}

We thank two anonymous reviewers of this journal who have considerably improved the presentation of this manuscript. This paper utilizes confidential CCHS data from Statistics Canada. Funding for this research by the Canadian Institutes of Health Research operating grant (reference number: MOP-97763) is gratefully acknowledged. A preliminary version of this paper was presented at the 47th Annual Conference of the Canadian Economics Association (CEA), held at the École des hautes études commerciales de Montréal, Montreal, Quebec, from May 30 to June 2, 2013 and at the Canadian Research Data Centre Network National Conference, University of Waterloo, Ontario, from October 3 to 4, 2013. We thank Emmanuelle Piérard and many participants of the CEA conference for their comments. Research assistance by Patrick Mroczek and Michael Lebenbaum is gratefully acknowledged. The views expressed in this paper, however, are those of the authors and do not necessarily reflect the views of any affiliated organization.

\section{REFERENCES}

Altonji JG, Elder TE, Taber CR. 2005. Selection on Observed and Unobserved Variables: Assessing the Effectiveness of Catholic Schools. Journal of Political Economy 113(1): 151-184.

Angrist JD, Imbens GW, Rubin DB. 1996. Identification of Causal Effects Using Instrumental Variables. Journal of the American Statistical Association 91(434): 444-455.

Balia S, Jones AM. 2008. Mortality, lifestyle and socio-economic status. Journal of Health Economics 27(1): 1-26. 
Baum CF, Schaffer ME, Stillman S. 2007. Enhanced routines for instrumental variables/generalized method of moments estimation and testing. Stata Journal 7(4): 465-506.

Bhattacharya J, Goldman D, McCaffrey D. 2006. Estimating probit models with self-selected treatments. Statistics in Medicine 25(3): 389-413.

Bound J, Jaeger DA, Baker RM. 1995. Problems with Instrumental Variables Estimation When the Correlation Between the Instruments and the Endogeneous Explanatory Variable is Weak. Journal of the American Statistical Association 90(430): 443-450. (Available from: http://www.jstor.org/stable/2291055?origin=crossref.)

Brown H, Roberts J. 2011. Exercising choice: The economic determinants of physical activity behaviour of an employed population. Social Science \& Medicine 73(3): 383-390.

Brown WJ, Burton NW, Rowan PJ. 2007. Updating the evidence on physical activity and health in women. American Journal of Preventive Medicine 33(5): 404-411.

Chen Y, Mao Y. 2006. Obesity and leisure time physical activity among Canadians. Preventive Mdicine 42(4): $261-265$.

Connor GS, Shields M, Tremblay MS, McDowell I. 2008. The feasibility of establishing correction factors to adjust selfreported estimates of obesity. Health Reports/Statistics Canada 19(3): 71-82.

Contoyannis P, Jones AM. 2004. Socio-economic status, health and lifestyle. Journal of Health Economics 23(5): 965-995.

Craig CL, Cameron C, Bauman A. 2005. Socio-demographic and lifestyle correlates of obesity-technical report on the secondary analyses using the 2000-2001 Canadian Community Health Survey. Canadian Institute for Health Information: Ottawa, ON.

Fogelholm M, Kukkonen-Harjula K. 2000. Does physical activity prevent weight gain - A systematic review. Obesity Reviews 1(2): 95-111.

Freedman DA, Sekhon JS. 2010. Endogeneity in Probit Response Models. Political Analysis 18(2): 138-150.

Godley J, McLaren L. 2010. Socioeconomic Status and Body Mass Index in Canada: Exploring Measures and Mechanisms. Canadian Review of Sociology 47(4): 381-403.

Grossman M. 2000. The human capital model. In Handbook of Health Economics, Volume 1A, New York: Elsevier; 347-408.

Hagberg LA, Lindholm L. 2010. Measuring the time costs of exercise: a proposed measuring method and a pilot study. Cost Effectiveness and Resource Allocation 8(1): 9.

Hatziandreu EI, Koplan JP, Weinstein MC, Caspersen CJ, Warner KE. 1988. A cost-effectiveness analysis of exercise as a health promotion activity. American Journal of Public Health 78(11): 1417-1421.

Humphreys BR, Ruseski JE. 2011. An Economic Analysis of Participation and Time Spent in Physical Activity. The BE Journal of Economic Analysis \& Policy 11(1): 1-36.

Humphreys BR, McLeod L, Ruseski JE. 2014. Physical activity and health outcomes: evidence from Canada. Health Economics 23(1): 33-54.

Imbens GW, Angrist JD. 1994. Identification and Estimation of Local Average Treatment Effects. Econometrica 62(2): 467-475, CR - Copyright \&\#169; 1994 The Econometri.

Kitchen P, Williams A, Chowhan J. 2011. Sense of Community Belonging and Health in Canada: A Regional Analysis. Social Indicators Research 107(1): 103-126.

Kleibergen F, Paap R. 2006. Generalized reduced rank tests using the singular value decomposition. Journal of Econometrics 133(1): 97-126.

Komlos J, Smith PK, Bogin B. 2004. Obesity and the rate of time preference: is there a connection? Journal of Biosocial Science 36(2): 209-219.

Laporte A, Nauenberg E, Shen L. 2008. Aging, social capital, and health care utilization in Canada. Health Economics, Policy, and Law 3(Pt 4): 393-411.

Maddala GS. 1983. Limited-dependent and qualitative variables in econometrics. Cambridge University Press: Cambridge [Cambridgeshire].

Maruyama S, Yin Q. 2012. The opportunity cost of exercise: Do higher-earning Australians exercise longer, harder, or both? Health Policy 106(2): 187-194.

Merchant AT, Dehghan M, Akhtar-Danesh N. 2007. Seasonal variation in leisure-time physical activity among Canadians. Canadian Journal of Public Health 98(3): 203-208.

Mullahy J, Robert S. 2010. No time to lose: time constraints and physical activity in the production of health. Review of Economics of the Household 8(4): 409-432.

Norton EC, Han E. 2008. Genetic information, obesity, and labor market outcomes. Health Economics 17(9): 1089-1104.

PHAC \& CIHI. 2011. Obesity in Canada. A joint report from the Public Health Agency of Canada and the Canadian Institute for Health Information, Ottawa, ON.

Romans S, Cohen M, Forte T. 2011. Rates of depression and anxiety in urban and rural Canada. Social Psychiatry and Psychiatric Epidemiology 46(7): 567-575.

Ross N. 2002. Community belonging and health. Health Reports 13(3): 33-39. 
Ross NA, Tremblay S, Khan S, Crouse D, Tremblay M, Berthelot JM. 2007. Body mass index in urban Canada: neighborhood and metropolitan area effects. American Journal of Public Health 97(3): 500-508.

Schneider BS, Schneider U. 2012. Health Behaviour and Health Assessment: Evidence from German Microdata. Economics Research International 2012: 1-13.

Shields M. 2008. Community belonging and self-perceived health. Health Reports 19(2): 51-60.

Smith PK, Bogin B, Bishai D. 2005. Are time preference and body mass index associated?: Evidence from the National Longitudinal Survey of Youth. Economics \& Human Biology 3(2): 259-270.

Staiger D, Stock JHJ. 1997. Instrumental variables regression with weak instruments. Econometrica 65: 557-586.

Stock JH, Yogo M. 2005. Testing for weak instruments in linear IV regression. In Identification and Inference for Econometric Models: Essays in Honor of Thomas Rothenberg, Andrews DWK, Stock JH (eds.), Cambridge University Press: Cambridge; 80-108.

Summerbell CD, Douthwaite W, Whittaker V et al. 2009. The association between diet and physical activity and subsequent excess weight gain and obesity assessed at 5 years of age or older: a systematic review of the epidemiological evidence. International Journal of Obesity 33(Suppl 3): S1-S92.

Tjepkema M. 2006. Adult obesity. Health Reports 17(3): 9.

Tucker P, Gilliland J. 2007. The effect of season and weather on physical activity: a systematic review. Public Health 121(12): 909-922.

US Department of Health and Human Services. 1996. Physical activity and health: report of the surgeon general. Department of Health and Human Services, CDC, Atlanta, GA.

Warburton DER, Nicol CW, Bredin SSD. 2006. Health benefits of physical activity: the evidence. Canadian Medical Association Journal 174(6): 801-809.

Wareham NJ, van Sluijs EMF, Ekelund U. 2005. Physical activity and obesity prevention: a review of the current evidence. Proceedings of the Nutrition Society 64(02): 229-247.

Waxman A, Assembly WH. 2004. WHO global strategy on diet, physical activity and health. Food and Nutrition Bulletin 25(3): 292-302.

Weinsier RL, Hunter GR, Heini AF, Goran MI, Sell SM. 1998. The etiology of obesity: relative contribution of metabolic factors, diet, and physical activity. The American Journal of Medicine 105(2): 145-150.

Wilde J. 2000. Identification of multiple equation probit models with endogenous dummy regressors. Economics Letters 69(3): 309-312.

Wister AV, Wanless D. 2007. A health profile of community-living nonagenarians in Canada. Canadian Journal on Aging 26(1): 1-18.

\section{SUPPORTING INFORMATION}

Additional supporting information may be found in the online version of this article at the publisher's website. 